\title{
Combination of non-invasive imaging techniques to characterize pigments in Buddhist thangka paintings.
}

\author{
J. Brocchieri, ${ }^{1}$ L. de Viguerie* ${ }^{2}$, C. Sabbarese ${ }^{1}$, M. Boyer $^{3}$ \\ ${ }^{1}$ Department of Mathematics and Physics, Università degli studi della Campania 'L. Vanvitelli' - \\ Caserta, Italy and CIRCE, Center for Isotopic Research on the Cultural and Environmental \\ heritage, Viale Carlo III, 156- San Nicola La Strada (CE) \\ ${ }^{2}$ Sorbonne Université, CNRS, Laboratoire d'Archéologie Moléculaire et Structurale (LAMS), 4 \\ place Jussieu, 75005Paris, France \\ ${ }^{3}$ Private restorer, 5 Rue Descombes, 75017 Paris, France
}

Keywords: MA-XRF, Hypersepctral imaging, identification and mapping of pigments, Thangkas

\begin{abstract}
Scanning macro-XRF, XRF point measurements and hyperspectral reflectance imaging in the visible and near-infrared range were combined to characterize the pigments of a Tibetan painting. The complementary use of the different investigation techniques allowed us to (i) clearly identify the pigments used by the artist, (ii) strengthen the few data present in historical and contemporary sources and (iii) provide data necessary for any accurate conservation treatment of the painting. The proposed methodology allows an in-depth characterization of the materials used in thangkas, with the identification of all the pigments used by Tibetan artists, as shown by the analyses of reference samples. In the present study traditional pigments, commonly cited in historical sources, were identified such as vermilion, minium, orpiment and azurite, but also more unusual compounds such as brochantite and antlerite (in blue/green areas). Elemental distribution images confirmed that some parts of the thangka were restored, without taking into account the original pigments or the original design. Underlying annotations and a carbon black under-drawing were highlighted by the application of near-infrared hyperspectral imaging technique, which proved to be particularly useful for the study of such paintings.
\end{abstract}

\section{INTRODUCTION}

Thangkas are sacred paintings, usually depicting a Buddhist deity ${ }^{[1]}$. They constitute a unique art form that belongs to Tibetan culture and is linked to the nomadic lifestyle of early Buddhist monks. 
Painting a thangka remains a religious practice in itself, and therefore follows ancestral traditions. The constituent materials have changed little since their appearance eight centuries ago ${ }^{[2,3,4,5]}$ : a cotton cloth or Chinese silk brocade, a natural glue sizing and a coating traditionally composed of chalk or kaolin, then a coloured layer made of mineral pigments and organic dyes. The technique is similar to that of the painters of the western Middle Ages. The main binder for these pigments was size or hide glue, the same gelatinous solution that was used for the preparation layer for the ground.

General information on Tibetan pigments is mainly based on literary sources and oral testimonies of modern-day painters. The now indispensable work of D.P. and J.A. Jackson brings together information on traditional techniques and materials from the testimonies of some twenty painters in India and Nepal, as well as from sources written by scholars ${ }^{[2]}$. A few analytical results on thangkas have also been published ${ }^{[1,6,7,8,9,10,11,12]}$. Duffy and Elgar, published in 1995 their extensive work on twenty-three thangkas from the 17th century combining in-situ X-ray fluorescence (XRF) and an indepth characterization of micro cross-sections ${ }^{[6]}$. Ten years later, a broad study was carried out by an Italian collaboration of researchers on more than thirty-five thangkas from the famous scientific missions of Giuseppe Tucci ${ }^{[8]}$. A series of investigations was performed with complementary in-situ non-destructive techniques (radiography, infrared reflectography and chemical analyses by colorimetry and X-ray fluorescence) focusing on the painting technique and the materials employed.

The study of thangkas is very often rendered particularly challenging by several factors: the presence of surface alteration products, degradation issues, later restorations and a general lack of information. We present here the first application of chemical imaging techniques to the study of thangka paintings. In the past few years, spectroscopic imaging techniques have proved their value in the investigation of historical paintings ${ }^{[13,14,15,16]}$. Scanning Macro-XRF (MA-XRF) and Hyperspectral Imaging (HSI) provide more representative results than in-situ punctual analyses or characterization of micro cross-sections. They can be a great help in the characterization of pigments and the possibility of mapping their presence in a painting. To set a methodology for the analysis of thankgas, the first step was to analyse reference pigments. Thereafter, one thangka from a French private collection was investigated during its conservation/restoration, using MA-XRF, XRF point measurements and HSI in the visible and near-infrared range. We provide detailed data relating to the materials and structure of the painting, the artist's palette, and the use of colour and pigment mixtures.

\section{THE SAMPLES}




\subsection{Reference pigments}

A set of 8 pigments, traditionally used in thangkas, was used as a reference, all purchased from Kremer Pigmente, Germany: malachite (10300), azurite (10200), vermilion (42000), orpiment (10700), minium (42500), indigo (36000), red aluminium lake of carminic acid (42100), extracted from cochineal, and calcite (58720). Kaolin was borrowed from the MNHN collection (geological sample from Combes des Eyzies, in France). They were analysed as pellets via XRF, visible and near-infrared HSI. X-ray diffraction was used to ensure the composition of the mineral pigments; the kaolin sample was found to be composed of kaolinite and quartz.

\subsection{The Thangka}

The thangka analysed (Figure 1), probably dated from the 18th century, and belongs to a French private collection. In transmitted light, the object was observed to consist of a canvas made of two pieces. As to its state of conservation, the gluing was weakened by multiple rollings and unrollings. Loss of colour and blackening is particularly observed particularly in the blues and greens, while the red, yellow, and orange areas are quite well preserved. Moreover, dirt due to smoke and handling covers the whole surface, disturbing its legibility.

The main deity is a Vaisravana: the king of the North and god of wealth ${ }^{[17-18]}$. Traditionally, he is mounted on a white lion, with the traditional mongoose in the left hand, regarded in Indian mythology as the animal that spits out jewels. He is accompanied by a suite known as the eight horsemen (Ashvapatis) ${ }^{[18]}$. 


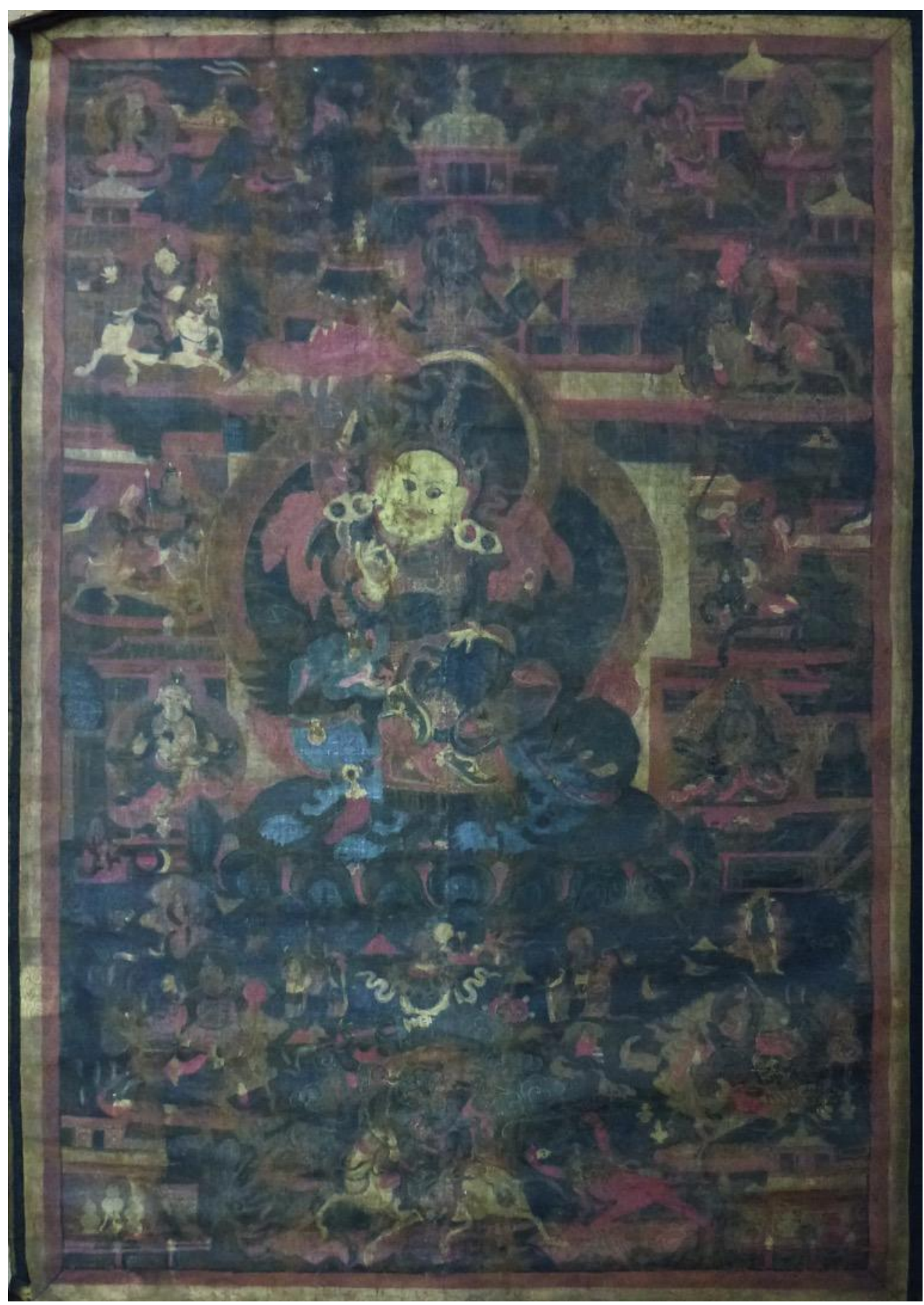

Figure 1: Photograph of the thangka analysed (French private collection).

\section{EXPERIMENTAL}

Point XRF and HSI measurements (visible and near infrared), were used on reference samples, complemented by X-Ray Diffraction (XRD) in the case of inorganic pigments.

On the thangka, 40 XRF spot analyses and 7 MA-XRF scans using various sizes and parameters (detailed below) were carried out. Visible and near-infrared HSI was also carried out over the entire painting, and in certain areas with a better resolution through "zoom" optics. Macrophotographs 
(Olympus OM-D E-M5 Mark II with a Olympus $60 \mathrm{~mm}$ macro lens) of the analysed areas were also recorded.

\section{MA-XRF}

The X-ray fluorescence apparatus was designed and developed in the laboratory, and is described elsewhere $^{[19]}$. In-house built MA-XRF instrument using a Pd anode transmission tube (Moxtek MAGNUM, Orem, UT) operated at $30 \mathrm{kV}$ and $0.1 \mathrm{~mA}(3 \mathrm{~W})$ and a SD-detector (active area of 25 $\mathrm{mm}^{2}, \mathrm{X}-123 \mathrm{FAST}$ SDD, Amptek, Bedford, MA). The X-ray tube was connected to the detector via a holder produced by $3 \mathrm{D}$ printing (fixing the angle between both to $45^{\circ}$ for single point analysis, or $32^{\circ}$ for imaging). A digital microscope (Dino-lite, AnMo Electronics Corporation, New Taipei City, Taiwan) and a laser distance measurement device (OADM20, Baumer, Frauenfeld, Switzerland) allow for measuring the position of the primary beam on the surface of the object. The beam size was approximately $1.2 \mathrm{~mm}$ and the typical working distance of $1 \mathrm{~cm}$. The system was used with manual translation stages for single-point analysis with acquisition time of $300 \mathrm{~s}$.

For XRF imaging the measurement head was mounted on a motorized XY stage with $20 \mathrm{~cm}$ travel range in both directions (M-403.8PD, Physik Instrumente (PI) GmbH \& Co. KG, Karlsruhe, Germany) with an additional manual $\mathrm{Z}$ translation. In all scans, the lateral resolution was defined by a step size of $0.8 \mathrm{~mm}$. The central area was investigated using a dwell time per pixel $0.2 \mathrm{~s}$.

For the evaluation of the raw full spectral XRF data, the dedicated PyMCA software was used ${ }^{[20]}$.

\section{HSI}

VNIR (Visible Near InfraRed) and SWIR (Short Wave InfraRed) hyperspectral camera by Specim (Oulu, Finland), mounted on translation stagewere used. Illumination was provided by two $20 \mathrm{~W}$ halogen lamps $1 \mathrm{~m}$ away. For the VNIR camera, the spectral range is $400 \mathrm{~nm}$ to $1000 \mathrm{~nm}$ with 212 wavelength channels (rebinned from 1200) with a spectral sampling of $2.8 \mathrm{~nm}$. For the SWIR camera, the spectral range is 1000 to $2500 \mathrm{~nm}$ with 280 wavelength channels and a spectral sampling of $12 \mathrm{~nm}$. The different acquisition parameters, camera and optics characteristics are reported in Table 1; for the SWIR camera, two optics with different spatial resolution were used. During the investigation, diffuse illumination was provided by two $20 \mathrm{~W}$ halogen lamp, placed at $0.4 \mathrm{~m}$ away.

Table 1: Cameras and optics characteristics, with acquisition parameters (italics).

\begin{tabular}{l|c|c}
\hline & VNIR (400-1000 $\mathbf{~ m m})$ & SWIR (1000-2500 $\mathbf{~ m})$ \\
\hline Spatial size & 1600 pixels & 380 pixels \\
\hline Spectral size & 1200 pixels & 280 pixels \\
\hline
\end{tabular}




\begin{tabular}{|c|c|c|c|c|}
\hline \multicolumn{2}{|c|}{ Spectral sampling } & $2.8 \mathrm{~nm}$ & \multicolumn{2}{|c|}{$12 \mathrm{~nm}$} \\
\hline \multicolumn{2}{|c|}{ Integration time } & $85 \mathrm{~ms}$ & \multicolumn{2}{|c|}{$13 \mathrm{~ms}$} \\
\hline \multicolumn{2}{|c|}{ Translation frequency } & $4 \mathrm{~Hz}$ & \multicolumn{2}{|c|}{$30 \mathrm{~Hz}$} \\
\hline \multicolumn{2}{|c|}{ Translation speed } & $1 \mathrm{~mm} / \mathrm{s}$ & \multicolumn{2}{|c|}{$5 \mathrm{~mm} / \mathrm{s}$} \\
\hline \multirow{3}{*}{$\begin{array}{l}\text { Optics } \\
\text { (Specim) }\end{array}$} & Туре & OL50 & OLES30 & OLES56 \\
\hline & Focal length & $50 \mathrm{~mm}$ & $30 \mathrm{~mm}$ & $56 \mathrm{~mm}$ \\
\hline & Distance & $950 \mathrm{~mm}$ & $1.0 \mathrm{~m}$ & $630 \mathrm{~mm}$ \\
\hline
\end{tabular}

The dedicated ENVI software (Harris Corporation, Melbourne, Florida, USA) was used for data treatment. The data was normalized with dark and bright field images using the Specim plug-in in ENVI. The spectral angle mapper (SAM) algorithm of ENVI was used to obtain reflectance map considering only a portion of the spectral range that contained the key spectral feature/s characteristic of the material to be mapped.

\section{RESULTS AND DISCUSSION}

\subsection{Reference Pigments}

According to Jackson ${ }^{[2]}$, thangkas are painted with a set of pigments, sourced from a number of sites in the Tibetan area, presented here by colour:

- blue and green: copper carbonates, respectively azurite and malachite. It is said that the artist's first task was to fill in large areas of sky and landscape with blues and greens.

- red: native cinnabar or its synthetic form vermilion $(\mathrm{HgS})$.

- orange: minium or its synthetic form red lead $\left(\mathrm{Pb}_{3} \mathrm{O}_{4}\right)$; realgar being mainly used for wall paintings.

- yellow: orpiment $\left(\mathrm{As}_{2} \mathrm{~S}_{3}\right)$.

Yellow and red ochres are also cited, but said to be used mainly for wall paintings (and not in thangkas), or as an undercoat for gold.

- white: calcium minerals, consisting mainly of calcium carbonate $\left(\mathrm{CaCO}_{3}\right)$.

- black: charcoal (wood chars) or lamp black.

Gold was also widely used as well as different organic dyes, such as indigo, and red « lac dye » (from the resin secreted by lac insects).

We present here the results obtained on the main pigments, as reference spectra. The complementary use of XRF and HSI (VNIR and SWIR) allow the complete identification of the whole palette (Table 2). Figure 2 shows the visible reflectance spectra of orpiment, minium, 
vermilion, malachite, azurite, indigo and a cochineal red lake (as a substitute of lac dye, with similar spectral features ${ }^{[21]}$ ). The SWIR reflectance spectra of malachite, azurite, calcite and kaolin, which display characteristics bands in this domain, are reported in Figure 3.
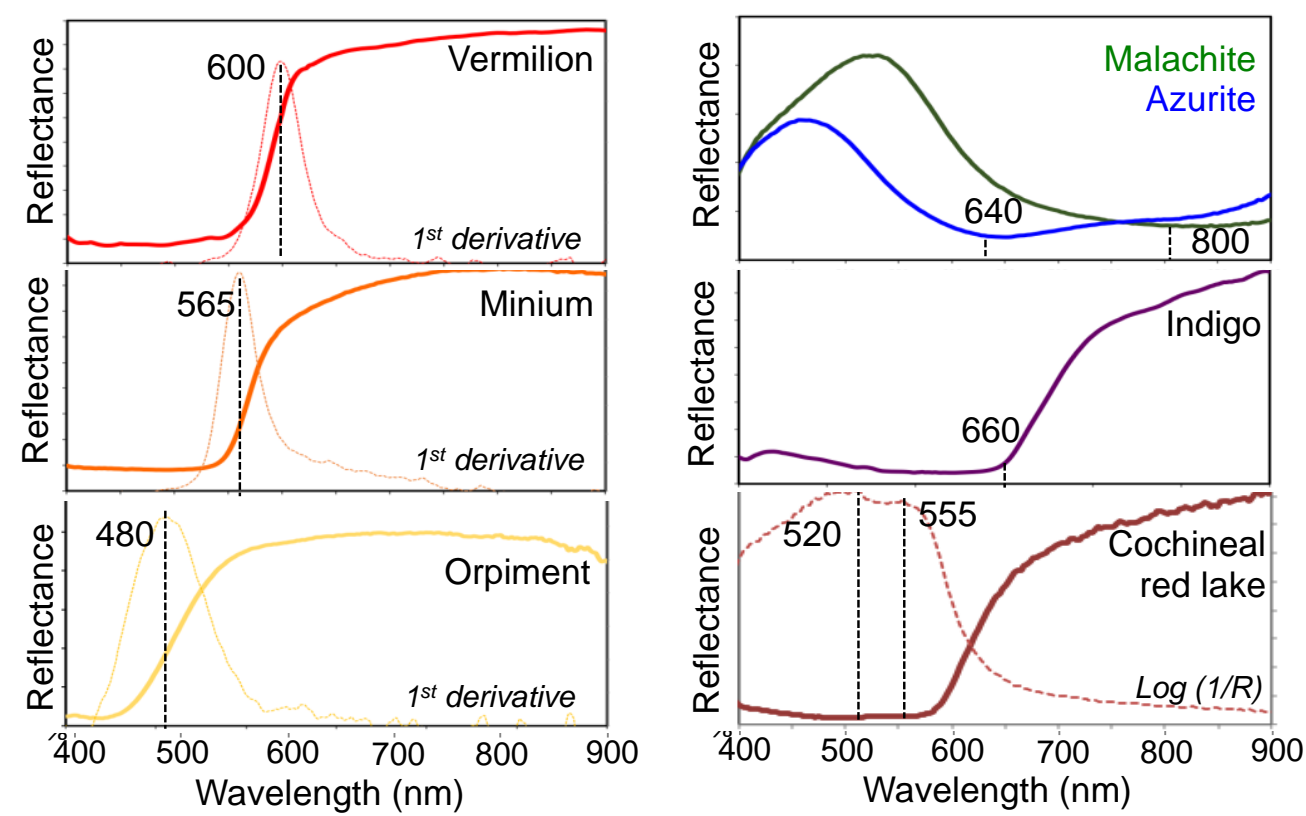

Figure 2: VNIR reflectance spectra of the main reference pigments (pellets).

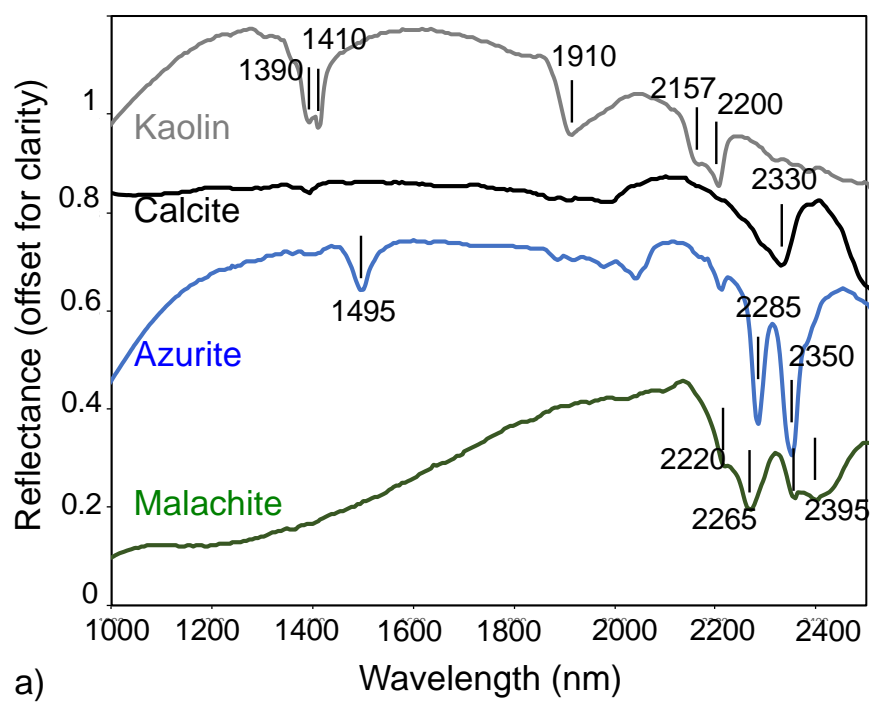

Figure 3: SWIR reflectance spectra of: a) reference samples, as pellets: kaolin (grey), calcite (black), azurite (blue) and malachite (green) (the spectrum of kaolin was offset for clarity).

Table 2: Main pigments and their characteristics

\begin{tabular}{l|c|c|c|c}
\hline & $\begin{array}{c}\text { Chemical } \\
\text { composition }\end{array}$ & $\begin{array}{c}\mathrm{XRF}-\text { elements } \\
\text { detected }\end{array}$ & $\begin{array}{c}\text { VNIR - band } \\
\text { position (nm) and } \\
\text { characteristics }\end{array}$ & $\begin{array}{c}\text { SWIR - bands } \\
\text { positions }\end{array}$ \\
\hline Orpiment & $\mathrm{As}_{2} \mathrm{~S}_{3}$ & $\mathrm{As}, \mathrm{S}$ & $480^{\mathrm{a}}$ & ${ }^{\mathrm{c}}$ \\
\hline Malachite & $\mathrm{Cu}_{2} \mathrm{CO}_{3}(\mathrm{OH})_{2}$ & $\mathrm{Cu}$ & $800^{\mathrm{b}}$ & $2220,2265,2355$, \\
\hline
\end{tabular}




\begin{tabular}{|c|c|c|c|c|}
\hline & & & & 2395 \\
\hline Azurite & $\mathrm{Cu}_{2}\left(\mathrm{CO}_{3}\right)_{2}(\mathrm{OH})_{2}$ & $\mathrm{Cu}$ & $640^{b}$ & $1495,2285,2350$ \\
\hline Vermillion & $\mathrm{HgS}$ & $\mathrm{Hg}, \mathrm{S}$ & $600^{\mathrm{a}}$ & $\mathrm{c}$ \\
\hline Indigo & $\begin{array}{c}\text { Organic (indigotin: } \\
\mathrm{C}_{16} \mathrm{H}_{10} \mathrm{~N}_{2} \mathrm{O}_{2} \text { ) }+ \\
\text { mineral substrate }\end{array}$ & l & $660^{b}$ & $\mathrm{c}$ \\
\hline $\begin{array}{l}\text { Cochineal red } \\
\text { lake }\end{array}$ & $\begin{array}{c}\text { Organic (carminic } \\
\text { acidC }_{22} \mathrm{H}_{20} \mathrm{O}_{13} \text { ) }+ \\
\text { mineralsubstrate }\end{array}$ & / & $520^{b}, 555^{b}$ & $\mathrm{c}$ \\
\hline Minium & $\mathrm{Pb}_{3} \mathrm{O}_{4}$ & $\mathrm{~Pb}$ & $565^{\mathrm{a}}$ & $\mathrm{c}$ \\
\hline Kaolin & $\mathrm{Al}_{2} \mathrm{Si}_{2} \mathrm{O}_{5}(\mathrm{OH})_{4}$ & $\mathrm{Al}, \mathrm{Si}$ & $\mathrm{c}$ & $\begin{array}{l}1390,1410,1910, \\
2200\end{array}$ \\
\hline Calcite & $\mathrm{CaCO}_{3}$ & $\mathrm{Ca}$ & $\bar{c}$ & $(1380), 2330,2520$ \\
\hline
\end{tabular}

${ }^{\mathrm{a}}$ Inflection point, ${ }^{\mathrm{b}}$ Apparent absorbance maximum, ${ }^{\mathrm{c}}$ No clear spectral feature detectable

\subsection{Results from the Vaisravana thangka}

\section{Identification and mapping of pigments}

The pigments identified by the different analytical methods, according to the characteristics indicated in table 2, are reported in table 3 (with typical spectra in Supporting Information). Elemental maps acquired by XRF (figure 4 and 7) allow a straightforward visualization of the pigments distribution, showing subtle differences in peak intensities. Distribution maps of pigments on restricted area could also be obtained thanks to hyperspectral data treatment as discussed in 4.3 and shown in figure 8.

Table 3: Identified pigments on the Vaisravanathangka.

\begin{tabular}{|c|c|c|c|c|}
\hline Colour & $\begin{array}{c}\text { XRF - } \\
\text { elements } \\
\text { detected }\end{array}$ & $\begin{array}{c}\text { VNIR } \\
\text { identification }\end{array}$ & $\begin{array}{c}\text { SWIR } \\
\text { identification }\end{array}$ & Pigment \\
\hline Yellow & As, $\mathrm{S}$ & Orpiment & $*$ & Orpiment \\
\hline Gold & $\mathrm{Au}, \mathrm{As}, \mathrm{S}$ & Gold *** & $*$ & Gold+Orpiment \\
\hline Orange & $\mathrm{Pb}$ & Minium & $*$ & Minium \\
\hline Red / Pink & $\mathrm{Hg}, \mathrm{S}$ & Vermilion & $*$ & Vermilion \\
\hline Flesh & $\mathrm{Pb}, \mathrm{As}$ & $\begin{array}{c}\text { Minium }+ \\
\text { orpiment }\end{array}$ & $*$ & Minium + orpiment \\
\hline Blue/Dark Blue & $\mathrm{Cu}(\mathrm{Mn})$ & $* *$ & Azurite & Azurite \\
\hline Green & $\mathrm{Cu}(\mathrm{Mn})$ & $*$ & $\begin{array}{c}\text { Mixture azurite+ } \\
\text { antlerite+ } \\
\text { brochantite }\end{array}$ & $\begin{array}{l}\text { Mixture azurite+ } \\
\text { antlerite+ } \\
\text { brochantite }\end{array}$ \\
\hline Silver-metallic blue & $\mathrm{Ag}(\mathrm{Cl})$ & $*$ & $*$ & ? (restoration) \\
\hline Preparation / white & $\begin{array}{l}\text { Si, Ti, Ca, Fe } \\
(\mathrm{K}, \mathrm{Cu})\end{array}$ & $*$ & $\begin{array}{l}\text { Mixture of clay } \\
\text { and Ca- } \\
\text { compounds }\end{array}$ & $\begin{array}{l}\text { Mixture of clay and } \\
\text { Ca- compound }\end{array}$ \\
\hline
\end{tabular}

* no characteristic feature observed by this technique; $* *$ results difficult to interpret due to the degradation state of the thangka; ${ }^{* * *}$ possible hypothesis that needed to be confirmed thanks to XRF (Figure S1). 


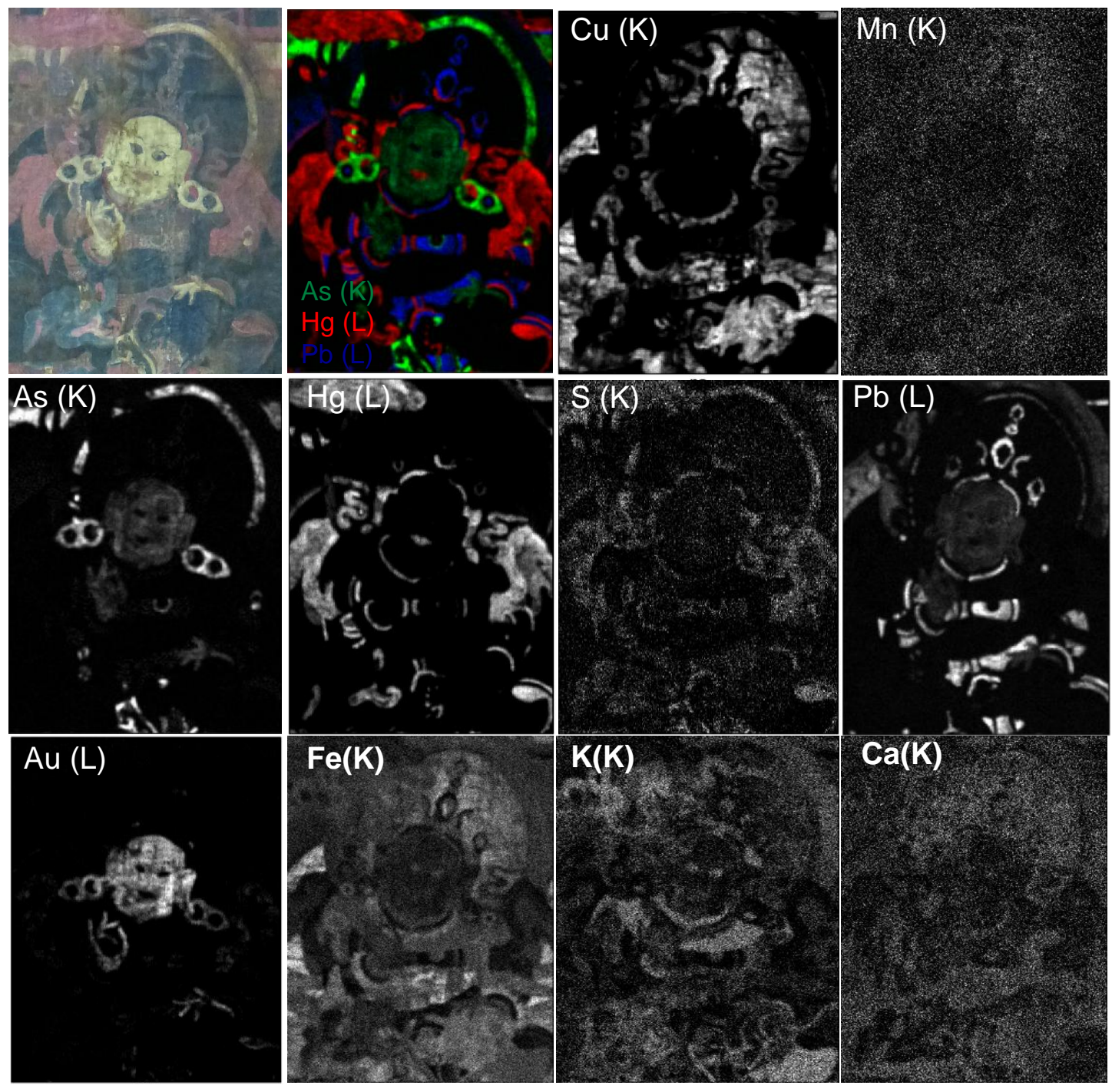

Figure 4: MA-XRF elemental distribution images of the main deity of the thangka with a brighter hue indicating a stronger signal. $1^{\text {st }}$ line, $1^{\text {st }}$ column: corresponding photograph of the zone; $1^{\text {st }}$ line, $2^{\text {nd }}$ column: overlay of $\mathrm{As}$ (green), $\mathrm{Hg}-\mathrm{L}$ (red) and $\mathrm{Pb}-\mathrm{L}$ (blue) respectively indicating the distribution of orpiment, vermilion and minium.

The main yellow pigment, actually used in almost all the whitish areas, is orpiment, as indicated by its reflectance spectrum (figure S2) and the presence of As and S.

Golden areas in the flesh of the main deity are mainly composed of gold ( $\mathrm{Au}$ ) as detected by X-ray fluorescence (figure 4 and S1) and suggested by the inflection point at $510 \mathrm{~nm}$ of the visible reflectance spectra (figure S1). Orpiment (As and S) is also present, probably applied as an underlayer of the gold. An ochre base is traditionally used but other bases exist such as mixtures of orpiment and calcium white ${ }^{[2]}$. On the contrary, the gold colour of the secondary divinities, such as dots (Figure 5) in the wrathful deity (below the main deity), correspond to orpiment only, being less precious zones or more altered ones.

The orange used to decorate clothing ornaments in the deity and horsemen is minium, identified thanks to the presence of $\mathrm{Pb}$ and its reflectance spectrum (figure $\mathrm{S} 2$ ). 
Red and Pink in the lips of the main deity, in the tongue of snow lion, in the aura of some of the horsemen and in many decorations of the painting, are composed of $\mathrm{Hg}$ and $\mathrm{S}$, which indicates the use of vermilion (confirmed by the reflectance spectrum, figure S2)

Some red parts, rather darkened today, indicate a strong $\mathrm{K}$ signal as visible in figure 4: in clothes but also in the eyes of the deity. This can be linked to the use of a lake pigment, prepared by precipitating or adsorbing an organic dye onto an inert inorganic substrate such as alum, traditionally potash alum $\mathrm{KAl}\left(\mathrm{SO}_{4}\right), 12 \mathrm{H}_{2} \mathrm{O}$. The presence of aluminium in these zones would confirm this use; however as the measurements were done in-situ, the absorption in air does not permit access to information for elements below silicon. The VNIR spectra of these areas do not contain any characteristic feature (except for a rise in the slope between 500 and $800 \mathrm{~nm}$ ) probably because of their darkening. We can thus only assume the use of a lake pigment, in accordance with the painting technique of thangkas: used for the eyes, clothes and also as a thin glaze on minium in the necklace.

The brown colour used for the flesh is composed of minium and orpiment, indicated by the presence of $\mathrm{As}$ and $\mathrm{Pb}$ detected by $\mathrm{X}$-ray fluorescence, and by the presence of the corresponding two inflection points in the visible reflectance spectrum.

Blue/dark blue colours mainly correspond to azurite identified thanks to its characteristic nearinfrared spectrum and to the presence of $\mathrm{Cu}$ detected by XRF. The XRF maps in figure 4 reveal the co-localization of $\mathrm{Cu}$ with significant traces of manganese $(\mathrm{Mn})$, probably linked to the azurite source (a natural ore). Here again, different shades of blue and paint aspects are visible, such as in the Lotus flowers (figure 5d): changing the pigment/binder ratio or the size of the particles can modify the aspect of the painting although based on the same pigment. $\operatorname{In}^{[2]}$, the authors report how Tibetan artists and pigment-makers obtain four kinds of blue, corresponding to four ranges of particle sizes, thanks to a "progressive sedimentation".

More greenish zones, or mixtures of darkened blue and green can also be found. A strong darkening of azurite is very commonly observed on thangkas, although not as yet clearly understood. In the thangka under investigation, if some zones could be attributed easily to azurite, such as the halo of the main deity, some blue/greenish areas presented more complex spectra, probably originating from mixtures of $\mathrm{Cu}$-compounds (figure 6b). In particular, it is possible to identify basic copper (II) sulfates, brochantite $\left[\mathrm{Cu}_{4} \mathrm{SO}_{4}(\mathrm{OH})_{6}\right]$, and antlerite $\left[\mathrm{Cu}_{3} \mathrm{SO}_{4}(\mathrm{OH})_{4}\right]$ : according to ${ }^{[22]}$, the brochantite SWIR spectrum shows a peak at $2334 \mathrm{~nm}$, and antlerite is characterized by a doublet at 2304 and $2352 \mathrm{~nm}$. Brochantite has been identified in thangkas by Duffy and Elgar ${ }^{[6]}$, but mixed with malachite in green zones. The authors explained it by their natural combination in malachite deposits. Here it is unclear whether these minerals were present in the original pigments (found in 
natural azurite and malachite ores, or produced for painting purposes) or are secondary products formed by the degradation of azurite and malachite ${ }^{[23]}$.

The pigments used for white and in the preparation layer were difficult to analyse due to the degraded and darkened aspect of the painting. Even for white, most of the areas analysed were in fact yellow, made with orpiment. One area, a white mountain covered with snow (visible clearly in figure 8c) is most probably painted with a white pigment; its XRF spectrum shows the presence of $\mathrm{Fe}, \mathrm{Ti}, \mathrm{K}, \mathrm{Ca}, \mathrm{S}$ and $\mathrm{Si}$ but also $\mathrm{Cu}$ (probably originating in the surrounding blue sky), and traces of $\mathrm{Hg}$ and As that may have been added to the ground. As calcite and kaolin are indicated in the sources as used for white pigments and in the preparation layer, we compare in figure 6a the SWIR spectrum of this area to the ones of the calcite and kaolin reference samples. A calcite compound, together with the textile support, can explain the main bands observed. According to ${ }^{[24,25]}$, a cellulose fibre (such as cotton, most probable in the case of a Tibetan artwork) exhibits features at $2275 \mathrm{~nm}, 2105 \mathrm{~nm}$ and $1930 \mathrm{~nm}$, and a very broad band centered at ca. $1490 \mathrm{~nm}$. Minor supplementary bands and slight displacements observed in our spectrum can also be due to the addition of other clay compounds (i.e. calcium, magnesium and aluminium silicates).

Figure 5: Macrophotographs of selected zones in the thangka under investigation: a) and b) golden dots on the deity; c) and d) $\mathrm{Cu}$-based pigment showing various shades and appearance. In c) a green colour is visible at the edge of the paint indicating a possible mixture with malachite. In d), from the Lotus flowers, two different appearances, probably resulting from different paint formulations.
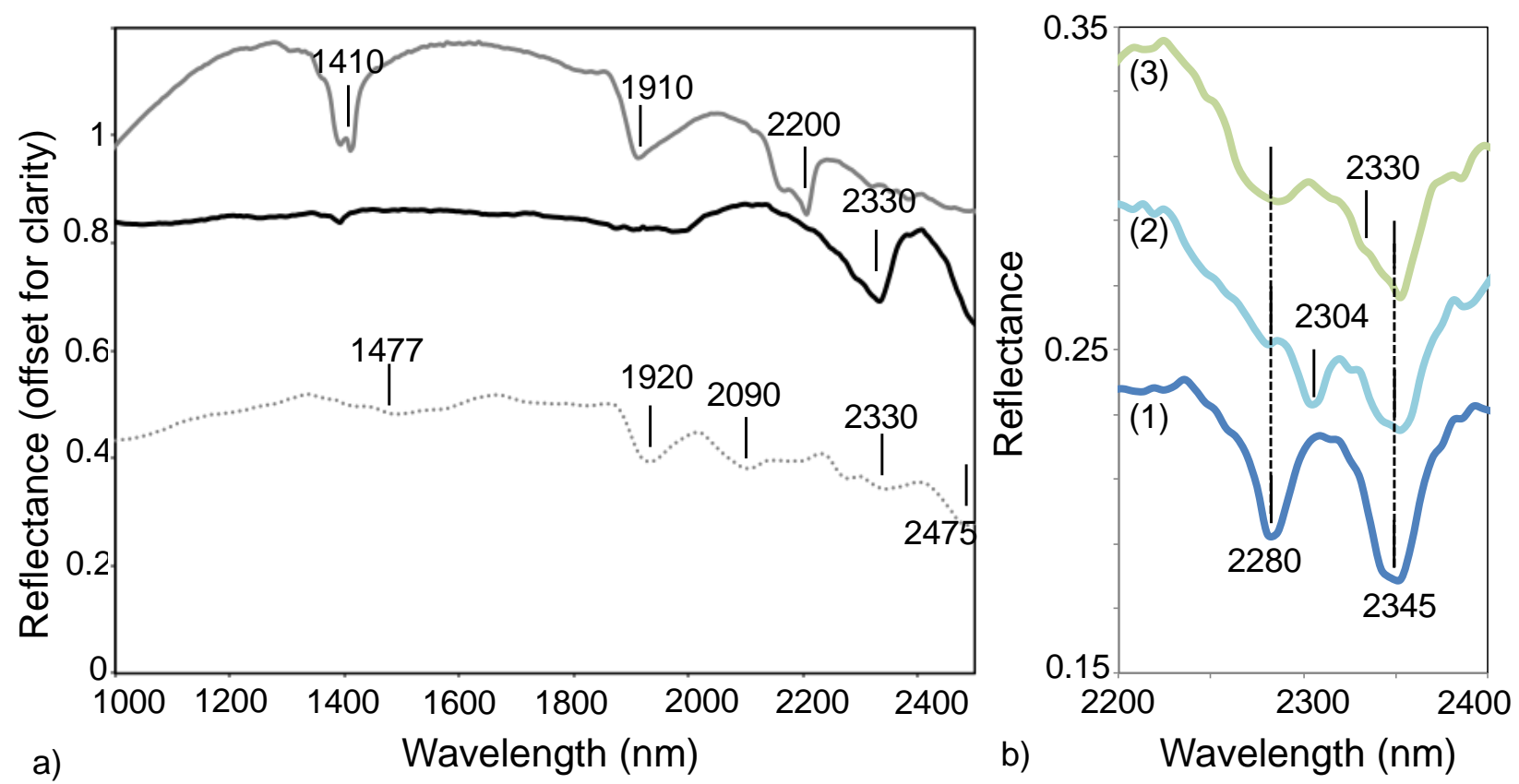

Figure 6: SWIR reflectance spectra of: a) reference samples as pellets: kaolin (grey, offset for clarity), calcite (black) and a white zone corresponding to snow on a mountain (grey dots); b) 
blue/greenish zones in the analysed thangka: (1) blue halo around the head of the deity, (2) and (3) greenish area indicated by a red circle in figure 8 .

\section{Revealing inaccurate past restorations}
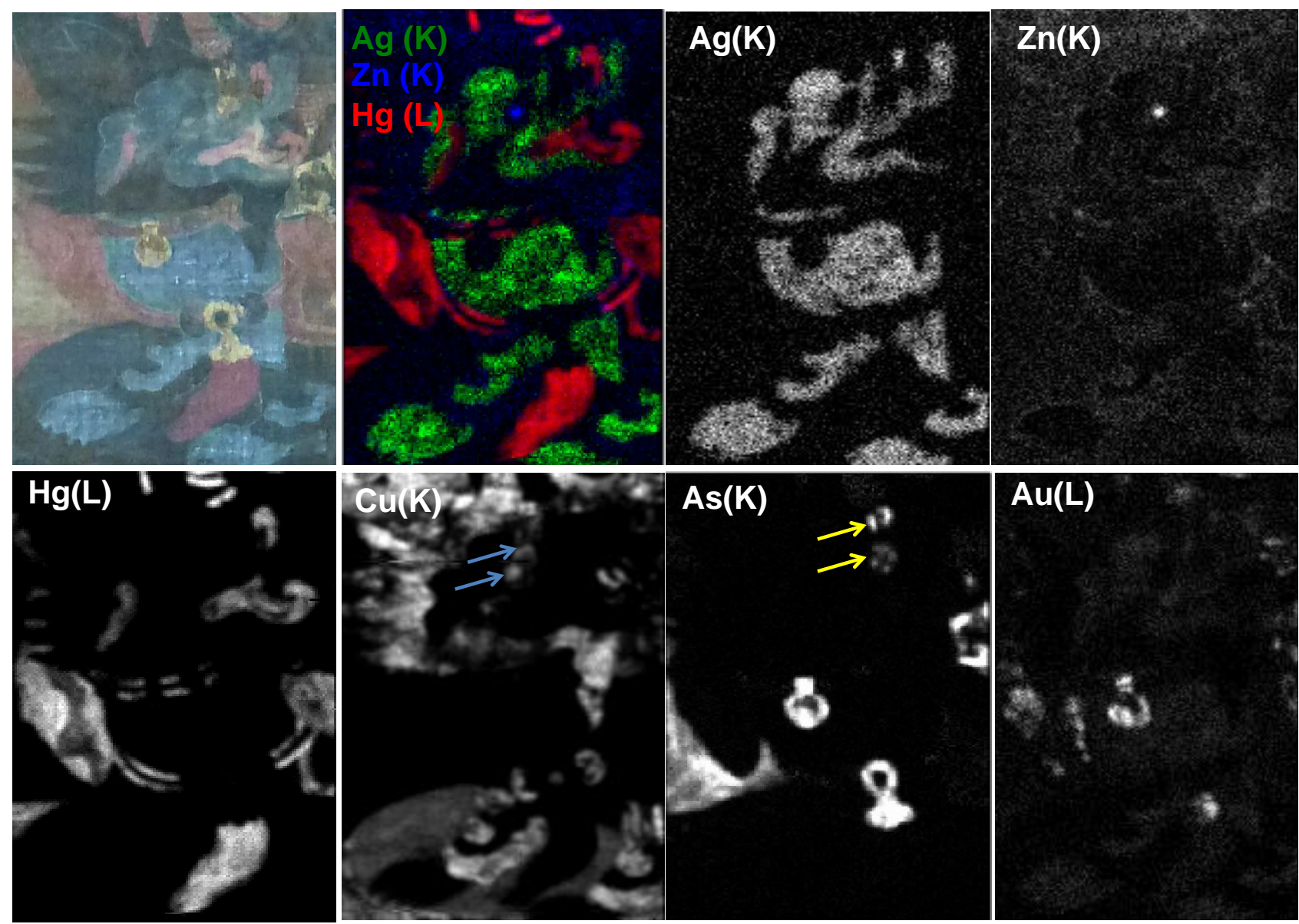

Figure 7: MA-XRF elemental distribution images of the snow lion, with a brighter hue indicating a stronger signal. $1^{\text {st }}$ line, $1^{\text {st }}$ column: corresponding photograph of the zone; $1^{\text {st }}$ line, $2^{\text {nd }}$ column: overlay of $\mathrm{Ag}-\mathrm{K}$ (green), $\mathrm{Hg}-\mathrm{L}$ (red) and $\mathrm{Zn}-\mathrm{K}$ (blue). In the $\mathrm{Cu}-\mathrm{K}$ and $\mathrm{As}-\mathrm{K}$ maps, arrows highlight bright areas, original position of respectively the eyebrows and the eyes.

When painting a thangka, the artist uses variations in mattness and gloss to create perspective and depth (by playing with pigments of different particle size and therefore different proportions of binder). The entire thangka now appears matt, as a result of the surface dust, except for the lion which stands out, glossy. This visual perception seems to be linked to a later restoration, as indicated by:

- the presence of silver in the fur of the snow lion, which is traditionally white and appears now of a metallic grey colour with blue reflections(figure 7and S3).

We can assume here that a restorer used metallic silver, probably crushed silver leaf, to render the luminous aspect of the snow lion. Silver is not commonly found in thangkas as it was more prone to tarnish and darker than gold, but widely used in Tibetan sculpture. 
- the presence of zinc in one of the snow lion's eye, probably indicating zinc white (used only from the $19^{\text {th }}$ century).

This restoration did not take into account the original pigments and/or the original drawing and thus changed its meaning: it disturbs not only the legibility of the object but also its iconography. Although we see now two eyes placed horizontally (one of zinc white and the other one, probably original, of orpiment), they were probably originally placed vertically as traditionally, turned towards to the deity (arrows in the As map, figure 7). This is confirmed by the position of the original eyebrows, indicated by the two $\mathrm{Cu}$ dots seen in the XRF maps: common iconography represents the snow lion with blue or green eyebrows (thangkas 16512 and 5160 from the Guimet museum $^{[18]}$ ).

\section{Construction and colour codes}

Before drawing the artist had to prepare the ground of the thangka on which the main lines of orientation were drawn. The central vertical axis is the most important because it allows the centre of the painting to be located, around which the artist would plan the rest of the composition. The correct establishment of the vertical and horizontal axes was also important from a religious standpoint. Thangkas are an expression of religious ideals through art; their figures (the ideal bodily forms of enlightened beings) have to be on a particular and precise position with respect to the central axis. Once the painting surface had been determined and its central axis established; the painter began the actual work of sketching. Traditional thangkas also exhibit colour codes written with charcoal on the ground, written by the main artist as a guide for other artists and apprentices, as previously observed by Duffy and Elgar ${ }^{[6]}$.

Infrared reflectography is a key technique to investigate thangkas revealing these underdrawings as part of the history of the thangka. As already observed in the context of paintings, near infrared HSI can be used as "improved reflectography"[26]; it revealed here the beauty of the underlying drawing (Figure 8), barely visible today due to the state of degradation of the work of art. The diagonal lines drawn by the author can be seen under the main drawing in figure 8a. Colour notations do not seem to have been used extensively for this thangka; we found only one sign that may be a colour notation. However, it was not possible to confirm the nature of this sign, in relation to the existing literature ${ }^{[1,2,6,8]}$. As it is located in greenish foliage, we may relate it to the notation 'pa' (English spelling) abbreviation for the Tibetan word malachite, as observed by Duffy and Elgar ${ }^{[6]}$ in rock crags, garments, jewels, and foliage of all the Shambhala paintings they analysed. The corresponding pigment was found to be a mixture of malachite and brochantite. Here the greenish colour is not related to the presence of malachite but to a mixture of azurite, antlerite and 
brochantite. It is thus difficult to reach a conclusion, which emphasizes the necessity of carrying out further scientific investigations on thangkas to better be able to define the pigments used, and how these can be described by Tibetan colour notations. 

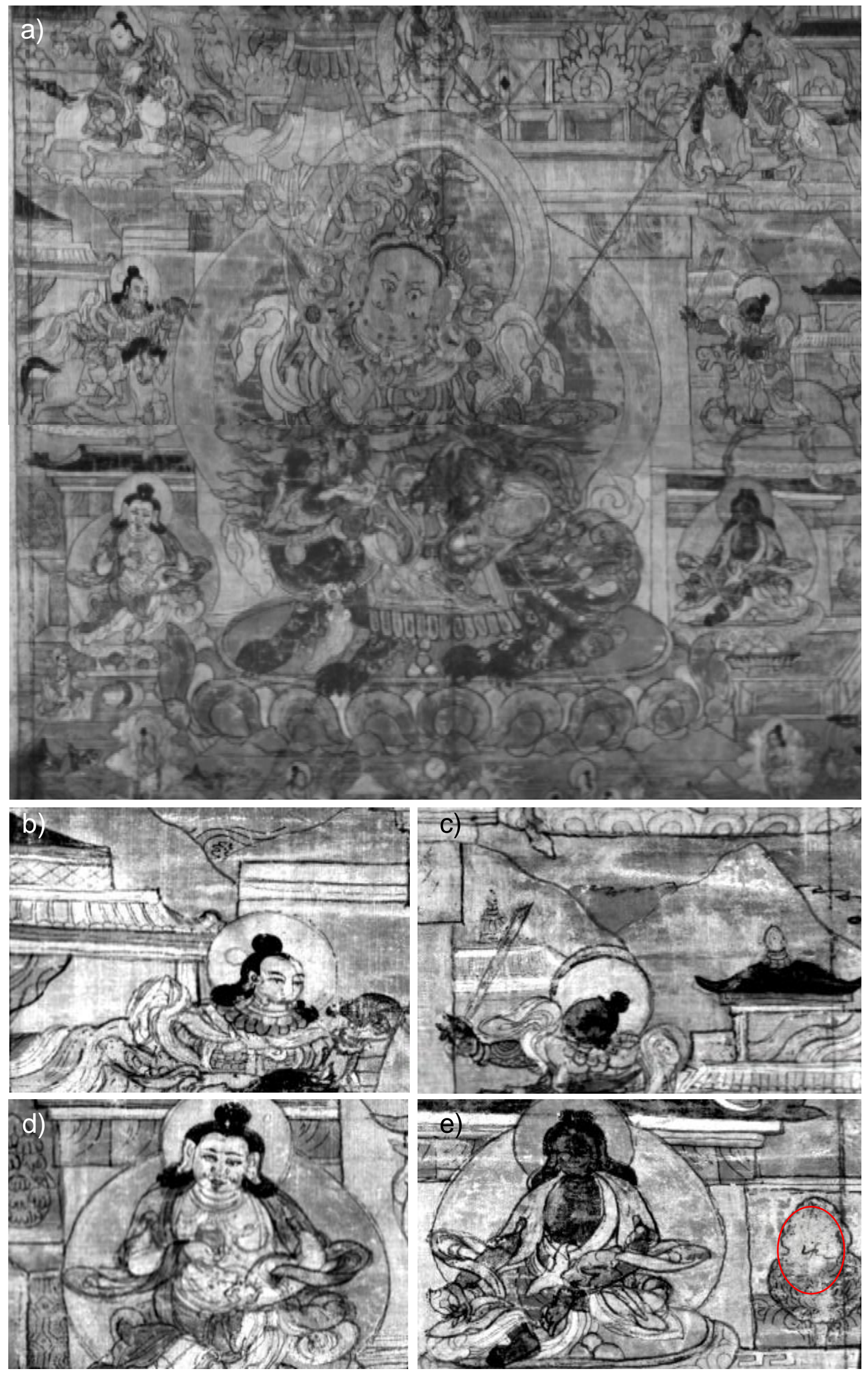
Figure 8: SWIR images of the thangka (from 1650 to $1750 \mathrm{~nm}$ ), witha "zoom" configuration from b) to e) (see Experimental). In e) the red circle indicates a sign, possibly a colour notation.

\subsection{Discussion: advantages and limits of the methodology for the analyses of thangkas}

The complementary use of XRF mapping, visible and near-infrared HSI techniques allow one to identify and map all the pigments listed as traditional in Tibetan paintings. The main limitation concerning the identification of pigments was here the state of conservation of the thangka analysed, which did not allow the identification of organic colourants.

Concerning imaging, we presented here "improved infrared reflectography" images, obtained thanks to near infrared HSI, and distribution maps of pigments obtained thanks to MA-XRF. However as pigments are employed mainly pure in thangkas, one can use classification methods for the hyperspectral data treatment, when the state of degradation of the artwork allows it. It was here possible to provide distribution maps of pigments but only on very restricted area. The exact procedure for obtaining these images (spectral range, use of the derivative data...) has to be defined for each pigment according to its absorption characteristics. Different procedures are shown in figure 9: vermilion, minium and orpiment maps obtained from XRF and visible HSI, and azurite map obtained from SWIR imaging. It should be noted that both XRF and visible HSI distribution maps are not exactly the same (particularly in the case of orpiment). This is mainly due to the choice of endmembers used for the SAM algorithm (Spectral Angle Mapper, algorithm used to obtain the characteristic images of the distribution of the pigment): only pure pigments were used, whereas the horse and the flesh of the horseman are made up of a mixture of orpiment and minium, clearly observable in the XRF map. It should also be noted that the SAM algorithm provides images in which the intensity of the signal cannot be linked to the pigment concentration, which is the case for XRF maps. One must also emphasize the difference in penetration of the different techniques: in the visible range, only the pigments at the surface are detected, whereas X-rays penetrate further depending on the chemical composition of the material. Under-layers also become visible in the near-infrared data. This can be a problem for spectral interpretation, making it valuable from an imaging point of view as it can reveal underlying drawings and compositional changes, which are important steps in the composition. 

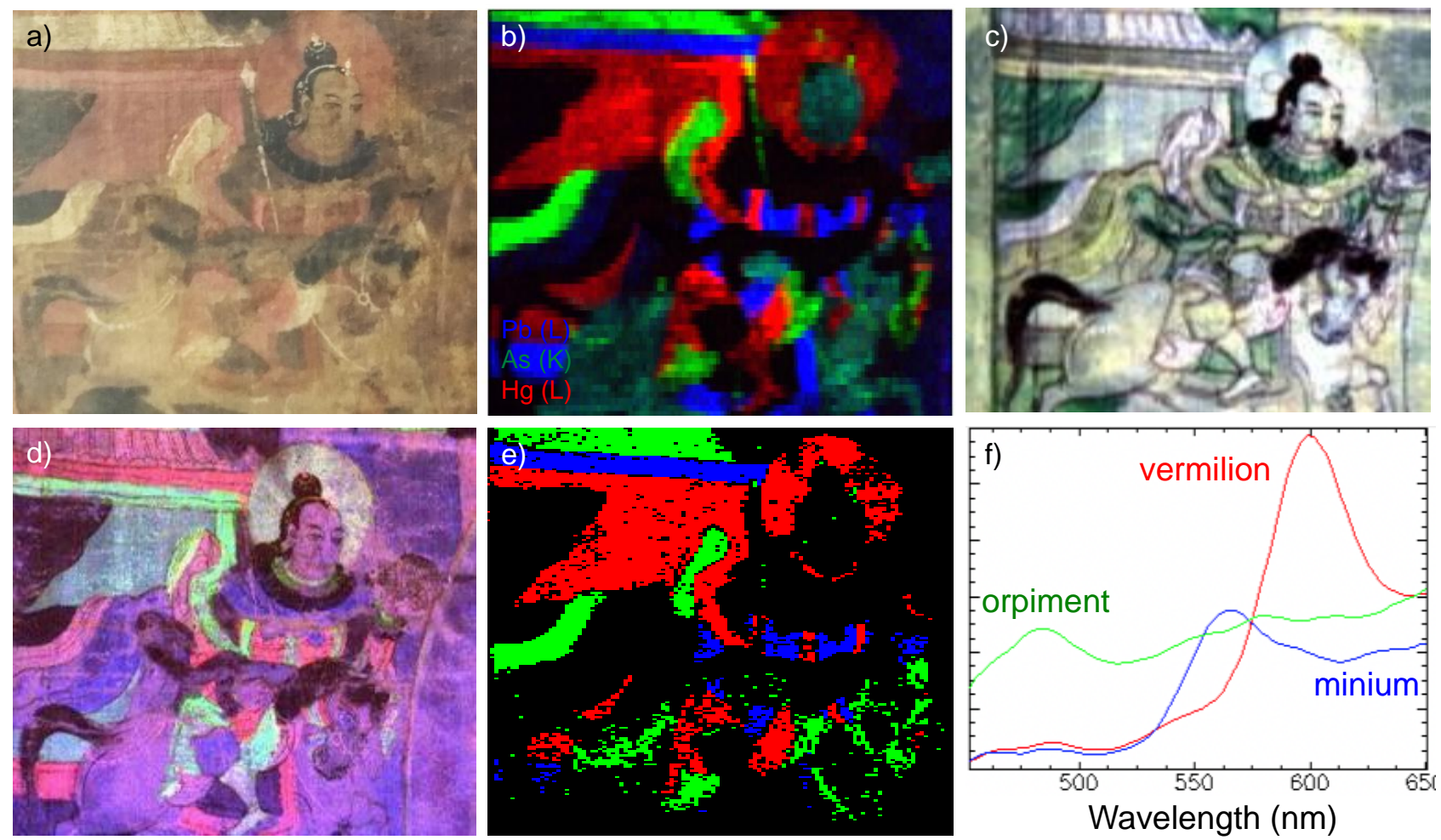

Figure 9:Comparison of the three imaging techniques on a selected zone: a) visible image; b) elemental maps acquired by XRF: $\mathrm{Hg}$ in red (vermilion), $A s$ in green (orpiment) and $\mathrm{Pb}$ in blue (minium); c) hyperspectral image in the near infrared (R, G, B respectively at 1000, 1450 and 2350 $\mathrm{nm})$ : azurite appears in green and carbon black in dark black; d) image obtained from the derivative of the visible hyperspectral data (R,G, B respectively at 564, 593 and $717 \mathrm{~nm}$ ); e) SAM (Spectral Angle Mapper) image obtained on the derivative data in the range 420-700 nm (tolerance angle 0.2 $\mathrm{rad}$ ), from pre-defined end members shown in $\mathrm{f}$ : in red vermilion, in green orpiment, in blue minium.

\section{Conclusions}

A methodology for the analysis of traditional Tibetan painting is proposed in the present work, thanks to the characterization of reference pigments and then applied to the in-depth investigation of a Vaisravana thangka. The complementary use of MA-XRF, XRF point measurements and HSI in the visible and near-infrared range allowed us to confirm the identification of the whole palette used by Tibetan artists as reported by historical and contemporary sources, and to provide data necessary for the correct conservation and restoration of the painting. To improve the proposed methodology in this case of strong darkening, the use of other complementary techniques can be proposed, such as Raman spectroscopy.

Near-infrared HSI, not commonly used until now on thangkas, provided invaluable information especially for the identification of white and blue/green pigments. Unusual Cu-compounds (chlorides or sulfates) were identified in blue/green areas. It would be interesting to go further, and see whether these pigments can be identified in more thangkas, and specify their origin and use (natural ore or alteration products). 
This study emphasizes the importance of increasing the available information on the material aspects of thangkas, carrying out more scientific investigations to better define the pigments used, their possible alterations, and how Tibetan colour notations can describe them.

\section{Acknowledgments}

The authors thank the infrared spectrometry platform of the MNHN analytical platform (and in particular X. Gallet for the database). We are also grateful to H. Glanville for her careful reading of the manuscript.

\section{References}

[1] G. Béguin, Les peintures du bouddhisme tibétain, RMN, Paris, 1995.

[2] D. Jackson, J. Jackson, Tibetan Thangka painting: methods \& materials, Serindia, London, 1984.

[3] J. Elgar, The Paper Conservator 2006 ;30 (1), 99-114.

[4] S. Cotte, Studies in Conservation $2011 ; 56,1-13$.

[5] P. Ricciardi, A. Pallipurath, in Tibetan Printing: Comparison, Continuities, and Change, (Ed :

H. Diemberger et al.), Brill, Leiden, Boston, 2016, pp. 485-500.

[6] K.I. Duffy, J.A. Elgar, in Historical painting techniques, materials and studio practice, Prepints of a symposium, university of Leiden, Netherlands, 26-29 June 1995 (Eds : A. Wallert, E. Hermens, M. Peek) Getty Conservation Institute, 1996, pp. 78-84.

[7] K. Duffy, J. Elgar in Scientific Research in the Field of Asian Art: Proceedings of the First Forbes Symposium at the Freer Gallery of Art, (Eds : P. Jett, J. G. Douglas, B. McCarthy, J. W. Winter), Archetype Publications Ltd, London, 1995, pp. 164-169.

[8] L. M. Tabasso, M. A. Polichetti, C. Seccaroni, DIPINTI TIBETANI dalle spedizioni di Giuseppe TucciMateriali e tecniche alla luce delle indagini non invasive, De Luca Editori d'Arte, Rome, 2011.

[9] J. Mass, J.F. Huang, B. Fiske, A. Shaftel, X. Zhang, R. Laursen, C. Shimoda, C. Matsen, C. Bisulca, in Proceedings of the Forum on the Conservation of Thangkas, Special Session of the ICOM-CC 15th Triennial Conference, New Delhi, India, September 26 2008, (Eds: M. Ballard, C. Dignard), ICOM -CC, 2009.

[10] E. R. Richard, J. Raman Spectrosc. $2010 ; 41,275-287$.

[11] E. R. Richard, Angew. Chem. Int. Ed. 2013; 52 (1), 61-67.

[12] Colinart S., Béguin G., in ICOM Comittee for conservation, 11th triennal meeting, Edinburgh, (Ed : J. Bridgland), James and James, London, 1996, pp. 206-210.

[13] M. Alfeld, L. de Viguerie, Spectrochim. Acta Part B. 2017; 136, 81-105.

[14] J.K. Delaney, J.G. Zeibel, M. Thoury, R. Littleton, M. Palmer, K. M. Morales, E. René de la Rie, A. Hoenigswald, App. Spectr. 2010; 64 (6), 584-594.

[15] K. Janssens, G. Van Der Snickt, M. Alfeld, P. Noble, A. van Loon, J. Delaney, D. Conover, J. Zeibel, J. Dik, Microchem. J. 2016; 126, 515-523.

[16] K.A. Dooley, D.M. Conover, L.D. Glinsman, J.K. Delaney, Angew.Chem. Int. Ed. 2014; 53, $13775-13779$.

[17] S. Tcheuky, Petite encyclopédie des divinités et symboles du boushisme tibetain, Claire Lumiere, Paris, 1998, pp. $402-407$.

[18] G. Béguin, S. Colinart, Artibus Asiae1994 ; 137-155. 
[19] L. de Viguerie, S. Rochut, M. Alfeld, P. Walter, S. Astier, V. Gontero, F. Boulch, Heritage Sci. 2018; 6 (1), 11.

[20] V. Solé, E. Papillon, M. Cotte, P. Walter, J. Susini, Spectrochim. Acta Part B 2007; 62 (1), 6368.

[21] M. Leona, J. Winter, Studies in Conservation2001;43 (3), 153-162.

[22] E. Catelliet al., Can hyperspectral imaging be used to map corrosion products on outdoor bronze sculptures?, J. Spectral Imaging 2018, 7, a10.

[23] S. Švarcová, D. Hradil, J. Hradilová, E. Kočí, P. Bezdička, Anal. Bioanal. Chem. 2009; 395 (7), 2037-2050.

[24] J.K. Delaney, P. Ricciardi, L. Glinsman, M.R. Palmer, J. Burke, Anal. Methods 2016; 8, 7886.

[25] M. Sohn, D.S. Himmelsbach, D.E. Akin, F.E. Barton, Textile Research Journal 1995; 75, 583590.

[26] J. K. Delaney, M. Thoury, J.G. Zeibel, P. Ricciardi, K.M. Morales, K.A. Dooley, Heritage Sci. 2016; 4. 1-6. 